\title{
Effect of Leptin Alone and in Combination with IL1 $\beta$ on Human Chondrocytes in a Pellet Culture System
}

\author{
Thanyaluck Phitak ${ }^{1}$, Sasimol Udomruk ${ }^{1}$, Kanchanit Boonmaleerat ${ }^{2}$, \\ Peraphan Pothacharoen', Dumnoensun Pruksakorn ${ }^{3}$, Prachya \\ Kongtawelert $^{1^{*}}$
}

\begin{abstract}
${ }^{I}$ Thailand Excellence Center for Tissue Engineering and Stem Cells, Faculty of Medicine, Chiang Mai University, Chiang Mai 50100, Thailand

${ }^{2}$ Faculty of Arts and Science, Western University, Kanchanaburi 71170, Thailand ${ }^{3}$ Musculoskeletal Research Laboratory, Department of Orthopedics, Faculty of Medicine, Chiang Mai University, Chiang Mai 50100, Thailand

*Corresponding author.E-mail: prachya.k@cmu.ac.th https://doi.org/10.12982/CMUJNS.2020.0051
\end{abstract}

Received: October 29, 2019

Revised: December 11, 2019 Accepted: December 20, 2019

\begin{abstract}
Osteoarthritis is the most common cause of disability among elderly, with obesity being a risk factor. The mechanical force on load-bearing joints in obese patients is known to induced Osteoarthritis development, however, low load-bearing joints in obese patients have also been found to develop Osteoarthritis. Leptin is a systemic hormone, associated with body-weight, and therefore may be the link between obesity and Osteoarthritis. This study aimed to investigate the effect of leptin on primary chondrocyte metabolism in a pellet culture system. The pellets were treated with IL1/ or leptin $(0.1-10 \mu \mathrm{g} / \mathrm{ml})$ or IL1及 and leptin $(0.1-10 \mu \mathrm{g} / \mathrm{ml})$ for 21 days. During that period, sulfated glycosaminoglycans (sGAGs) and hydroxyproline released in culture media and remaining in the pellets, as well as the expressions of ACAN, COL2A1, COL1A1, MMP3, MMP13 genes and MMP3, MMP13 enzymes were measured. Additionally, sGAGs and collagen accumulation in the extracellular matrix was determined by histological analysis. Leptin $(1.0-10 \mu \mathrm{g} / \mathrm{ml})$ was able to reduce the ECM molecule contents, both sGAGs and collagen, through up-regulation of MMPs expression, down-regulation of ACAN expression and induction of the dedifferentiation stage of chondrocytes. The effect of $10 \mu \mathrm{g} / \mathrm{ml}$ leptin was similar to IL1ß, the main cytokine involved in cartilage degradation. Interestingly, leptin had an additive effect with IL1及 on the reduction of pellet ECM molecule contents. This study shows that leptin can induce cartilage
\end{abstract}




\section{breakdown by down regulation of ECM molecules and up regulation of protease enzymes and has an additive effect with IL1ß on cartilage degradation.}

Keywords: Osteoarthritis, Chondrocyte, IL1 $\beta$, Leptin, Pellet culture

\section{INTRODUCTION}

Osteoarthritis (OA) is the most common cause of musculoskeletal system disability among elderly worldwide (Musumeci et al., 2015). The pathogenesis of OA involves an imbalance in the synthesis and degradation of cartilage tissue, primarily the extracellular matrix (ECM) containing type II collagen which encoded from $C O L 2 A l$ gene and proteoglycans such as aggrecan which is a main proteoglycan found in cartilage and encoded from ACAN gene. Cartilage tissue degradation is mediated by protease enzymes, matrix-metalloproteinases (MMPs) and a disintegrin and metalloproteinase with thrombospodin motifs (ADAMTSs), which are induced by pro-inflammatory cytokines, mainly IL1 $\beta$, TNF $\alpha$ and IL6. MMP3 and MMP13 are main enzymes that can degrade ECM of cartilage. Additionally, OA is also associated with body weight due to increased mechanical force on joints, resulting in the development of OA in load-bearing joints, such as the knees, especially in obese patients. Interestingly, obesity is also a risk factor for the progression of OA in low-weight bearing joints, such as the hands, which cannot be explained by increased mechanical force on the joints (Yusuf et al., 2010). Cytokines, including leptin, that systematically increase obesity may be involved in the weight associated development of OA.

Leptin, a $16-\mathrm{kDa}$ peptide hormone produced primarily by adipose tissue, is responsible for the metabolism of energy, with ability to regulate appetite and the consumption of energy (Ahima et al., 1996; Trayhurn, 2005). Studies have found higher levels of leptin in both obese subjects and OA patients compared to normal-weight and non-OA patients, respectively. Serum leptin concentration was found to be correlated with body weight, with higher levels in obese subjects $(31.3 \pm 24.1 \mathrm{ng} / \mathrm{ml})$ compared to normal-weight subjects $(7.5 \pm 9.3 \mathrm{ng} / \mathrm{ml})$ (Considine et al., 1996). In OA patients compared to non-OA patients, leptin levels were higher in the peripheral blood $(18 \pm 13 \mathrm{ng} / \mathrm{ml}$ and $73 \pm 61 \mathrm{ng} / \mathrm{ml}$ in normal and OA subjects, respectively) and in the synovial fluid $(2.05 \mathrm{ng} / \mathrm{ml}$, with a range of $1.0-4.6 \mathrm{ng} / \mathrm{ml}$, and $4.40 \mathrm{ng} / \mathrm{ml}$, with a range of $0.5-15.8 \mathrm{ng} / \mathrm{ml}$, in normal and OA subjects, respectively) (Otero et al., 2006; Ku et al., 2009; de Boer et al., 2012).

While there have been numerous investigations on the effect of leptin on cartilage metabolism, the results remain inconclusive. The contradictory reports on the effect of leptin may result from numerous factors, including the use 
of intact or isolated chondrocytes as a model, arthritic conditions of cartilage samples, in vitro culture condition, species of tissue/cell samples, the concentration of leptin used in the experiment and the gender or age of tissue/cell samples. Our previous investigation, on the effect of leptin in porcine cartilage explant and monolayer human primary chondrocyte cultures, found that only a supra-pathological concentration of leptin $(10 \mu \mathrm{g} / \mathrm{ml})$ alone and in combination with IL1 $\beta$ could induce cartilage degradation, while lower concentrations could not (Phitak et al., 2018). However, the model had several limitations. Firstly, different species were used for the explant culture and gene expression profiles of both cartilage matrix proteins and proteases in chondrocytes from monolayer culture were lower than those from cartilage tissue. But more importantly, there were dedifferentiated stages of chondrocytes in the monolayer human chondrocyte culture. The chondrocytic gene expression profiles differentially alter at various stages of passage (Lin et al., 2008). In the monolayer culture, chondrocytes typically devolve to a fibroblastic morphology and secrete type I collagen into the matrix, but lose the expression of type II collagen and aggrecan core protein, and interestingly, the dedifferentiated chondrocytes reverse their phenotype when condensed by continuous culture after reaching confluence (Schulze-Tanzil et al., 2002). Therefore, cell density is a critical requirement for stabilizing the chondrocyte phenotype, which does not change when chondrocytes are plated at high density in culture flasks (Ruggiero et al., 1993).

Pellet culture is a high-density cell culture that provides a threedimensional (3D) environment enabling cell-cell interactions and is used as a standard method for chondrocyte culture ( Srisuthtayanont et al., 2017; Witt et al., 2017; Ito et al., 2019). Additionally, it is well documented that all catabolic factors that induce cartilage degradation are induced by pro-inflammatory cytokines, mainly IL1 $\beta$, and studies have reported the synergistic effect of leptin with IL1 $\beta$ on the initiation of cartilage degradation (Koskinen et al., 2011; Phitak et al., 2018) Therefore, this study investigated the pellet culture of primary human chondrocytes in order to more precisely understand the effect of leptin on chondrocytes and also the additive or synergistic effects of leptin with IL1 $\beta$ in this model.

\section{MATERIALS AND METHODS}

\section{Reagents}

Tissue culture mediums and others related reagents were purchased from Gibco (Grand Island, NY, USA). Recombinant human IL1 $\beta$, OSM and leptin were purchased from Peprotech (NJ, USA). An RNA extraction kit was purchased from GE Healthcare (Buckinghamshire, UK). A Tetro cDNA ${ }^{\mathrm{TM}}$ synthesis kit and 2x Sensifast ${ }^{\mathrm{TM}}$ SYBR Lo-Rox mix was purchased from Bioline (London, UK). The human MMP3 and MMP13 ELISA kits were purchased from 
Elabscience (Texas, USA). Other reagents were purchased from Sigma-Aldrich and Invitrogen.

\section{Pellet culture and treatment}

Normal human articular cartilage was obtained from patients that underwent amputation of a lower limb following an orthopedics diagnosis of osteosarcoma at Maharaj Nakorn Chiang Mai Hospital, Faculty of Medicine, Chiang Mai University, Thailand. Full patient informed consent was obtained, and ethical approval was granted by the ethics committee of the Faculty of Medicine, Chiang Mai University, Thailand (approval code ORT-2557-02717). Orthopedic surgeons resected normal sections of cartilage from the amputated limbs of 2 female and 2 male patients aged 13 to 27 years. Primary chondrocytes were isolated from the intact cartilage by overnight trypsin digestion at $4{ }^{\circ} \mathrm{C}$ and subsequent 3-hour digestion with collagenase at $37{ }^{\circ} \mathrm{C}$. The cells were washed with PBS, then cultured in DMEM containing 10\% FCS in a humidified incubator with $5 \% \mathrm{CO}_{2}$ at $37{ }^{\circ} \mathrm{C}$, until the high-density primary monolayer cultures achieved confluence. The human articular chondrocytes (HACs) at passage 3 were used for the pellet culture. Trypsinized $5 \times 10^{5}$ HACs were centrifuged at $160 \mathrm{~g}$ for 5 minutes and cultured with $500 \mu \mathrm{l}$ chondrogenic medium $(10 \%$ FCS/DMEM, Insulin-Transferrin-Selenium (ITS $1 \times$ ), 25 $\mathrm{g} / \mathrm{ml}$ ascorbic acid 2-phosphates and $10^{-7} \mathrm{M}$ dexamethasone) in $15 \mathrm{ml}$ conical tubes. Pellets were grown in a humidified incubator with $5 \% \mathrm{CO}_{2}$ at $37{ }^{\circ} \mathrm{C}$ for 3 days before being treated with $0.05 \mathrm{ng} / \mathrm{ml} \mathrm{IL1} \beta, 0.05 \mathrm{ng} / \mathrm{ml}$ oncostatin M (OSM), 0.1-10 $\mu \mathrm{g} / \mathrm{ml}$ leptin, $0.05 \mathrm{ng} / \mathrm{ml} \mathrm{IL} 1 \beta+0.1 \mu \mathrm{g} / \mathrm{ml}$ leptin, $0.05 \mathrm{ng} / \mathrm{ml} \mathrm{IL} 1 \beta+1.0 \mu \mathrm{g} / \mathrm{ml}$ leptin, $0.05 \mathrm{ng} / \mathrm{ml}$ IL $1 \beta+10 \mu \mathrm{g} / \mathrm{ml}$ leptin or $0.05 \mathrm{ng} / \mathrm{ml}$ IL1 $\beta+0.05 \mathrm{ng} / \mathrm{ml}$ OSM. The conditioned media was collected and changed on Day 4, 7, 11, 14, 17, and 21 of the culture. The collected media was used in the measurement of sGAG, hydroxyproline releases and MMPs levels. Pellets were collected at Day 7 for the measurement of gene expressions and at Day 21 for the measurement of sGAG, hydroxyproline contents, DNA content and histological analysis.

\section{Cytotoxicity test}

The viability of HACs in the pellet was investigated by the measurement of lactate dehydrogenase (LDH) activity in the conditioned media (Roussel and Stallcup, 1965). The pellets were treated with $10 \mathrm{mM}$ of $\mathrm{H}_{2} \mathrm{O}_{2}$, which was used as a positive control for cell death. $100 \mu \mathrm{l}$ samples of the pellets were mixed with $625 \mu \mathrm{l}$ of $1.6 \mathrm{mg} / \mathrm{ml} \beta$-DPNH in phosphate buffer (PB) and $375 \mu \mathrm{l}$ of $2 \mathrm{mM}$ pyruvate in $\mathrm{PB}$ then incubated at $37{ }^{\circ} \mathrm{C}$ for 30 minutes. The pyruvate substrate was catalyzed by $\mathrm{LDH}$ in a sample to lactate. The remaining pyruvate was reacted with $1 \mathrm{ml}$ of $20 \mathrm{mg} / \mathrm{dl}$ 2,4-dinitophenyl-hydrazine in $1 \mathrm{~N} \mathrm{HCl}$ at room temperature for $20 \mathrm{~min}$, then stopped using $0.4 \mathrm{~N} \mathrm{NaOH}$. The absorbance was measured at $450 \mathrm{~nm}$. 


\section{Histological analysis}

The collected pellets at the end of culture were fixed overnight in $4 \%$ paraformadehyde, embedded in wax, then cut into $4 \mu \mathrm{m}$ thick sections. The sections were stained with hematoxylin-eosin (H\&E), Safranin O and Masson's trichrome stain to evaluate the effects of the treatments on cell pathology, glycosaminoglycans (GAG) content and collagen content in the pellet, respectively (Goldner, 1938). H\&E and Masson's trichrome staining was conducted by the Department of Pathology, Faculty of Medicine, Chiang Mai University.

\section{Measurement of sulfated GAGs (sGAGs) content}

At the end of the culture, the pellets were collected and digested overnight with papain at $37{ }^{\circ} \mathrm{C}$. The papain-digested pellets and the collected conditioned media were used for the measurement of sGAGs by dimethylmethylene blue (DMMB) assay (Farndale et al., 1986). Shark cartilage chondroitin sulfate C (Sigma Aldrich, USA) was used as the standard. The DMMB solution was added to the diluted sample, standards and appropriate blank solutions prior to measuring the absorbance at $525 \mathrm{~nm}$ by a micro-plate reader spectrophotometer.

\section{Measurement of hydroxyproline content}

Hydoxyproline content was measured in papain-digested pellets and collected conditioned media. The samples were hydrolyzed using $6 \mathrm{~N} \mathrm{HCl}$ for 24-hours at $110{ }^{\circ} \mathrm{C}$. After hydrolysis, the samples were freeze-dried and resolubilized with distilled $\mathrm{H}_{2} \mathrm{O}$. The hydroxyproline in each sample was oxidized to a pyrrole using chloramine $\mathrm{T}$ at $\mathrm{pH} 6$. The samples were mixed with diluent solution (67\% propan-2-ol), oxidant solution (50 $\mathrm{mM}$ chloramine $\mathrm{T})$, and color reagent (7.5\% dimethylamino benzadehyde in propan-2-ol) (Kolar, 1990). The reaction was performed at $70{ }^{\circ} \mathrm{C}$ for $10-20 \mathrm{~min}$. Absorbance was read at $540 \mathrm{~nm}$ using a microtitre-plate reader.

\section{Measurement of mRNA expression by real-time PCR}

After 7 days of treatment, mRNA was extracted from the pellets using Illustra $^{\mathrm{TM}}$ RNASpin Mini RNA Isolation Kits (GE Healthcare) following the manufacturer's protocol. $500 \mathrm{ng}$ of mRNA was converted to cDNA using a Tetro cDNA Synthesis Kit (Bioline). The genes of interest were amplified using primers, as shown in Table 1, and 2x Sensifast ${ }^{\mathrm{TM}}$ SYBR Lo-Rox Mix (Bioline) with a 7500 Fast Real-Time PCR System (Applied Biosystems). Reactions were performed for 40 cycles at $95^{\circ} \mathrm{C}$ for denaturation, $60{ }^{\circ} \mathrm{C}$ for annealing and $72{ }^{\circ} \mathrm{C}$ for extension. The data was collected and the level of gene expression of the samples was compared to that of the house-keeping gene, GADPH, which was calculated using the $2^{-\Delta \Delta C t}$ method (Livak and Schmittgen, 2001). 
Table 1. The primer sequences used for Real-time PCR.

\begin{tabular}{|c|l|}
\hline Gene & \multicolumn{1}{|c|}{ Primer sequences } \\
\hline \multirow{2}{*}{ GAPDH } & F: 5'-AGGGCTGCTTTTAACTCTCGT-3' \\
\cline { 2 - 2 } & R: 5'-CCCCACTTGATTTTGGAGGGA-3' \\
\hline \multirow{2}{*}{ ACAN } & F: 5'-ACTTCCGCTGGTCAGATGGA-3' \\
\cline { 2 - 2 } & R: 5'-TCTCGTGCCAGATCATCACC-3' \\
\hline \multirow{2}{*}{ COL2A1 } & F: 5'-GGTGGCTTCCATTTCAGCTATG-3' \\
\cline { 2 - 2 } & R: 5'-TTGCAGTGGTAGGTGATGTTCTG-3' \\
\hline \multirow{2}{*}{ COL1A1 } & F: 5'-CAGCCGCTTCACCTACAGC-3' \\
\cline { 2 - 2 } & R: 5'-TTTTGTATTCAATCACTGTCTTGCC-3' \\
\hline
\end{tabular}

\section{Measurement of MMP3 and MMP13 levels in the conditioned media}

MMP3 and MMP13 levels in the conditioned media were measured using ELISA kits (Elabscience, Texas, USA) according to the manufacturer's protocol. Briefly, $100 \mu \mathrm{l}$ of the standard and samples were added to the ELISA plate, which was pre-coated with an antibody specific to human MMP-3 or MMP-13, and then incubated for 90 minutes at $37{ }^{\circ} \mathrm{C}$. Subsequently, a biotinylated detection antibody specific for human MMP-3 or MMP-13 and Avidin-Horseradish Peroxidase (HRP) conjugate was added to each micro plate well and incubated. Free components were washed away, then the substrate solution was added to each well. The enzyme-substrate reaction was terminated by the addition of the stop solution. The optical density (OD) was measured using a spectrophotometer at OD $450 \mathrm{~nm}$.

\section{Data and statistical analyses}

The results from the experiments were expressed as mean \pm SEM from triplicate samples of each of three independent experiments. Statistically significant values were compared using one-way analysis of variance (ANOVA) and values of $P<0.05$ were considered significant. 


\section{RESULTS}

\section{Effect of leptin alone and in combination with IL1 $\beta$ on the pathological condition of chondrocyte in pellet culture}

The expression of $A C A N, C O L 2 A 1$ and $C O L 1 A 1$, investigated by real-time PCR in both chondrocytes cultured in monolayer and pellet systems, can be used to confirm that the pellet culture system can decrease dedifferentiated stages of chondrocytes. ACAN, COL2AI and COLAl encode for aggrecan the core proteins of the most apparent proteoglycan in cartilage, alpha-chain of type II collagen the main collagen type found in cartilage and type I collagen, respectively. Specific phenotype of chondrocyte can be showed using a ratio of COL2A1 to COL1A1 expression, where a decrease in the ratio implies the loss of specific phenotype of chondrocyte. The results from the expressions of all measured genes found an increase in pellet culture compared to that in monolayer culture including COL1A1. The ratio of COL2A1 to COL1A1 expression had a significant increase in the pellet culture system compared to that in monolayer culture, which suggests that the pellet culture system can decrease dedifferentiated stages of cultured chondrocytes (Figure 1).

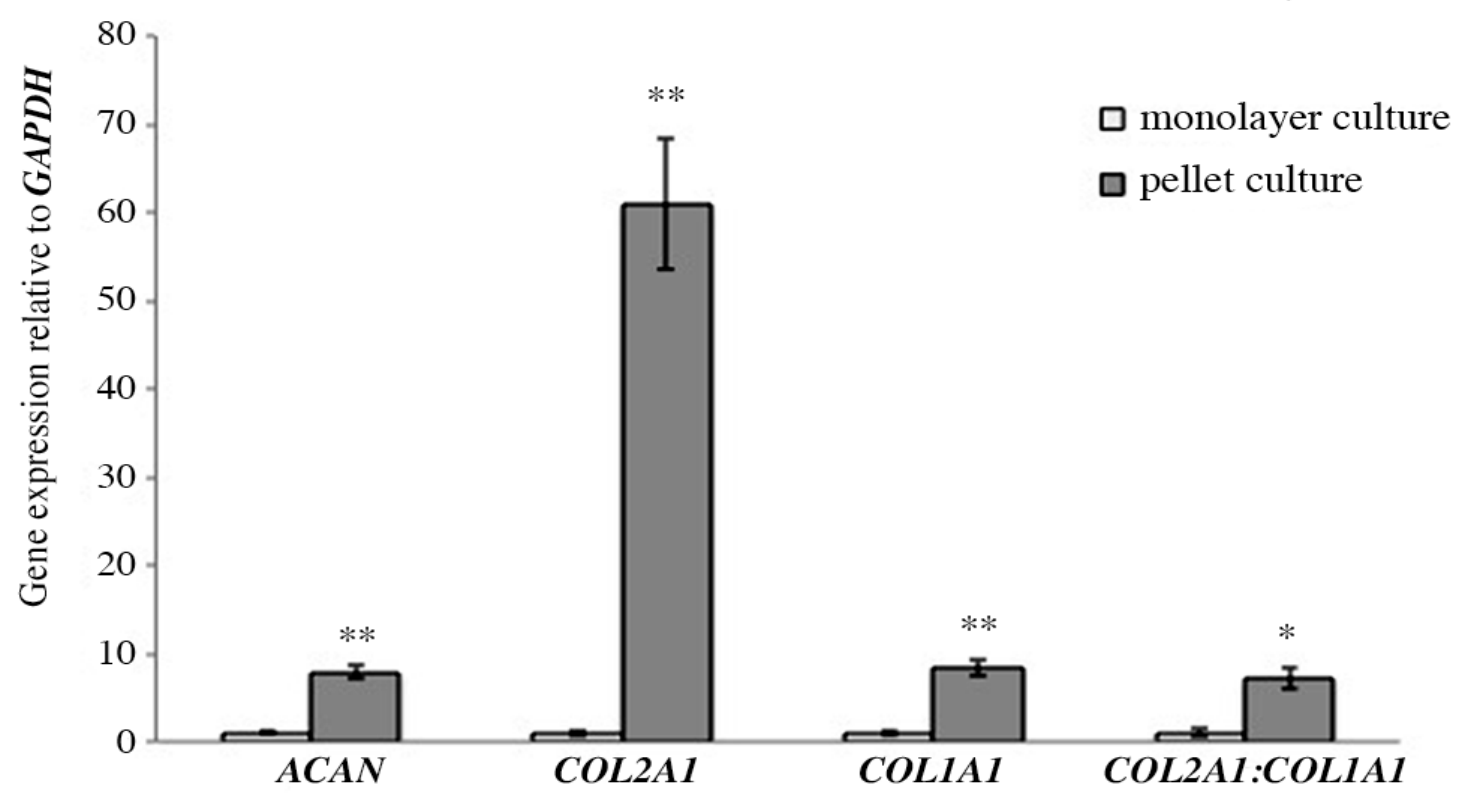

Figure 1. The expressions of ACAN, COL2A1, COL1A1 and ratio of COL2A1:COL1A1 expression in chondrocytes cultured in monolayer and pellet systems (Day 7).

Note: $* P<0.05$ and $* * P<0.01$ compared with control. 
LDH activity in cultured media was measured to investigate the cytotoxicity of all treatments to the chondrocytes in the pellets. No toxicity was found in any of the treatments (Figure 2). Moreover, there have been published reports which described that oncostatin M (OSM) has been observed in inflammatory diseases such as arthritis and multiple sclerosis. Its role in arthritis is its capacity to synergize the action of other inflammatory cytokines: e.g. IL-1, TNF-a, IL-17 and LPS (Koshy et al., 2002; Phitak et al., 2012). Thus, cotreatment of the pellets with IL-1 $\beta$ and OSM was also investigated as a positive control. After 21 days of culture, the pellets were collected for histological analysis. H\&E staining of the control group (Figure 3a) showed a rounded shape and good distribution in extracellular matrix (ECM). The morphology of chondrocytes was significantly changed and the distribution of cells was not well organized in IL1 $\beta$ and IL1 $\beta+O S M$ treated groups (Figure $3 b, c$ ), and in the leptintreated groups the morphology of chondrocytes was slightly changed compared to that of the control (Figure 3d-f). Interestingly, in the IL1 $\beta+$ leptin treated groups (Figure 3g-i), the morphology and the distribution of chondrocytes was similar to IL1 $\beta$ and IL1 $\beta+O S M$ treated groups.

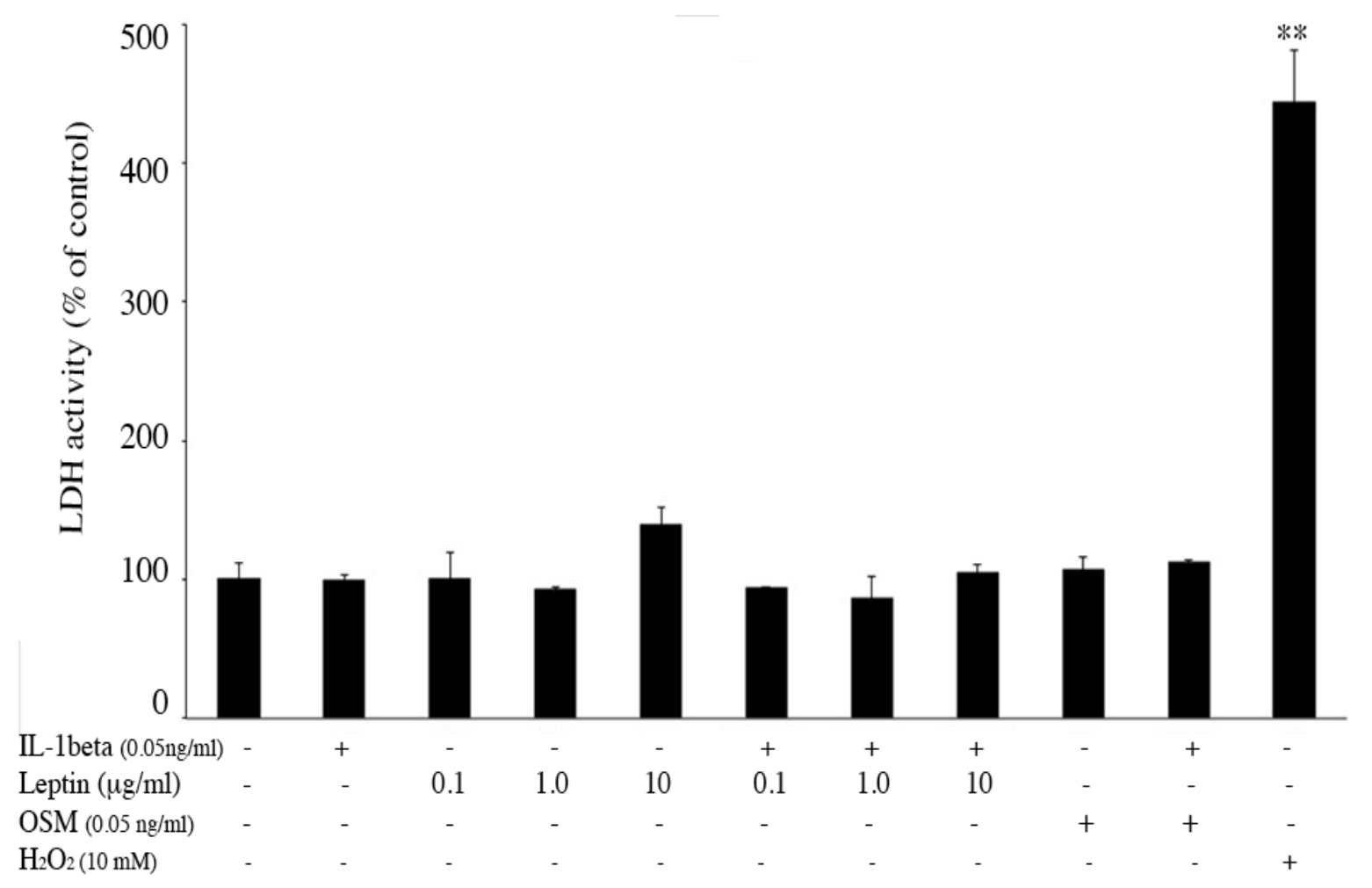

Figure 2. The effect of IL1 $\beta$, leptin, OSM, IL1 $\beta+$ leptin and IL1 $\beta+$ OSM on chondrocyte viability in the pellets. The pellets treated with $10 \mathrm{mM}$ $\mathrm{H}_{2} \mathrm{O}_{2}$ were used as a positive control.

Note: $* * P<0.01$ compared with control. 


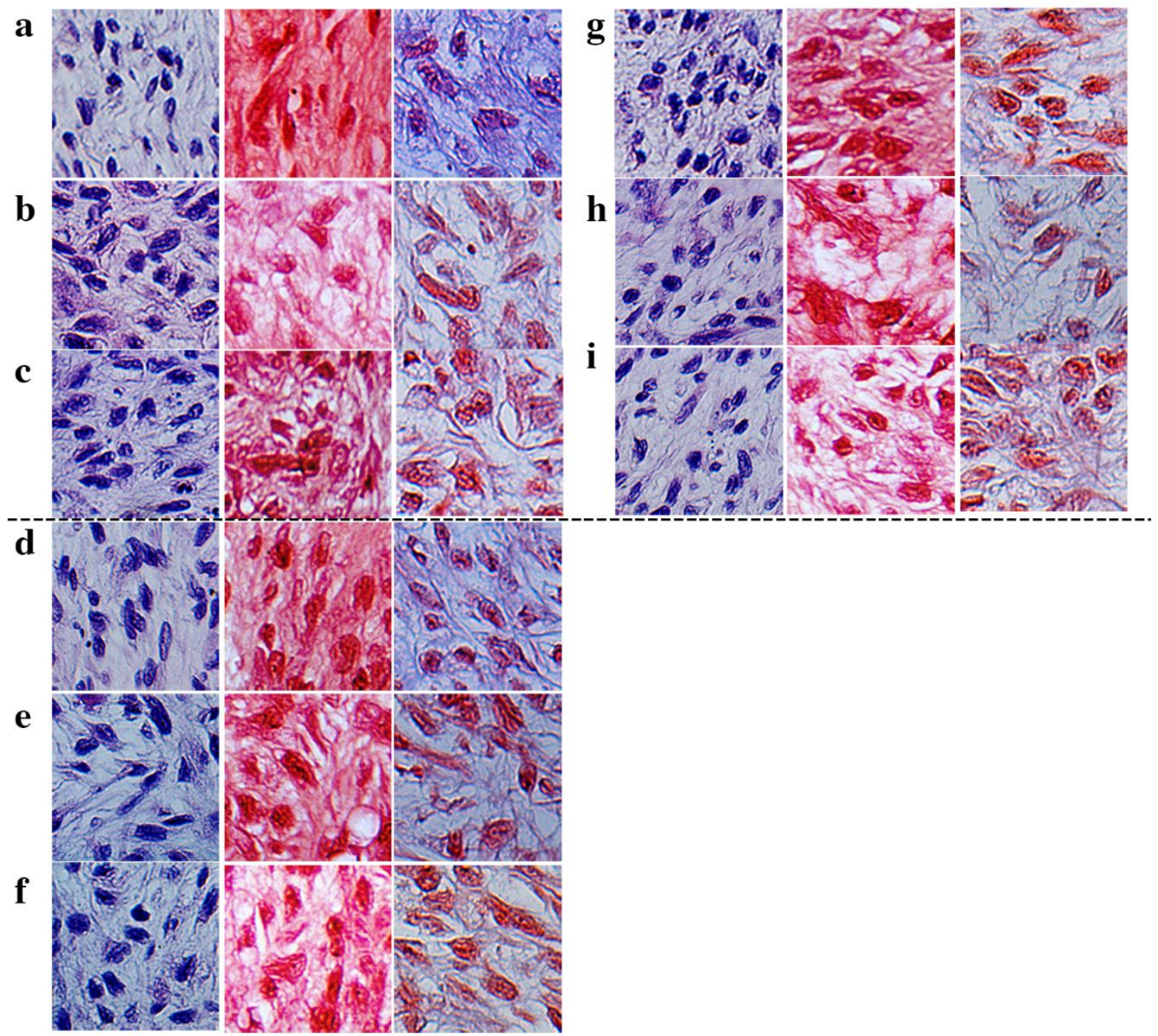

Figure 3. Human chondrocyte pellet staining included H\&E staining (first column), safranin $\mathrm{O}$ staining (second column), and Masson's trichrome staining (the last column). The photos were taken at 40X magnification in the middle of the pellet. The analysis was performed in the control (a), IL1 $\beta$ treated (b), IL $\beta+$ OSM treated (c), $0.1 \mu \mathrm{g} / \mathrm{ml}$ leptin treated (d), $1.0 \mu \mathrm{g} / \mathrm{ml}$ leptin treated (e), $10 \mu \mathrm{g} / \mathrm{ml}$ leptin treated (f), IL1 $\beta+0.1 \mu \mathrm{g} / \mathrm{ml}$ leptin treated (g), IL $1 \beta+1.0 \mu \mathrm{g} / \mathrm{ml}$ leptin treated (h), IL $1 \beta+10 \mu \mathrm{g} / \mathrm{ml}$ leptin treated (i), groups. The representative figures are from only 1 donor sample. 


\section{Effect of leptin alone and in combination with IL1 $\beta$ on glycosaminoglycans (GAGs) content}

The measurement of extracellular matrix (ECM) molecule contents, sGAGs, that are release from the pellets into cultured media and the remaining sGAGs in the pellet, can be used to investigate the effect of leptin alone and in combination with IL1 $\beta$. The results of the level of sGAG remaining in the pellets measured by DMMB assay (Figure 4) was similar to that measured by safranin $\mathrm{O}$ staining (Figure 3). The stained GAG in the ECM of the pellet was shown in red color and the intensity of red color indicates level of GAG. The results from the IL1 $\beta$ treatment found significantly decreased sGAGs content remaining in the pellet (Figure 4C), and also decreased sGAGs released into the media, which may indicate that IL $1 \beta$ is able to reduce the production of sGAGs in the pellet (Figure 4A). Leptin at $1.0 \mu \mathrm{g} / \mathrm{ml}$ increased sGAGs released into the media but this concentration could not significantly decrease the sGAGs remaining in the pellet (Figure 4A, C). Interestingly, the highest concentration of leptin (10 $\mu \mathrm{g} / \mathrm{ml}$ ) had the same effect as IL1 $\beta$ (Figure $4 \mathrm{~A}, \mathrm{C}$ ). The combination of IL1 $\beta$ and $10 \mu \mathrm{g} / \mathrm{ml}$ of leptin showed a greater increase in sGAGs released into the media and greater decrease in sGAGs remaining in the pellets when compared to IL- $1 \beta$ treated alone and more significantly when compared to IL1 $\beta+O S M$. 


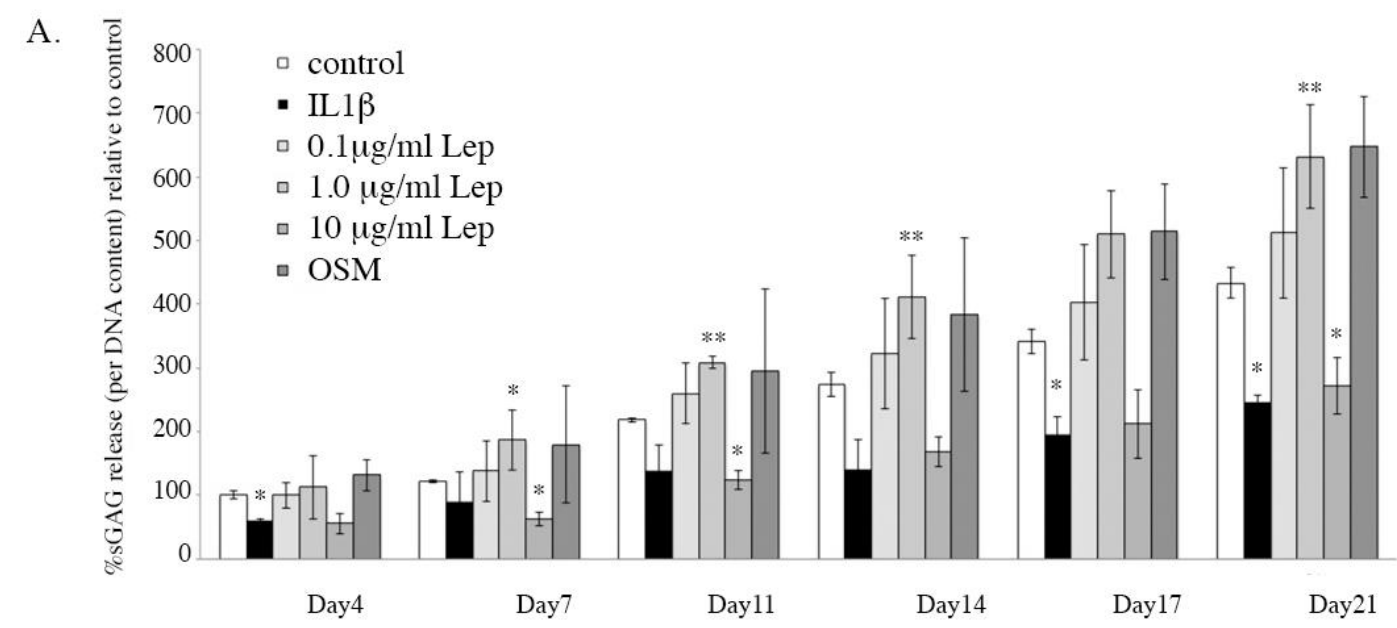

B.
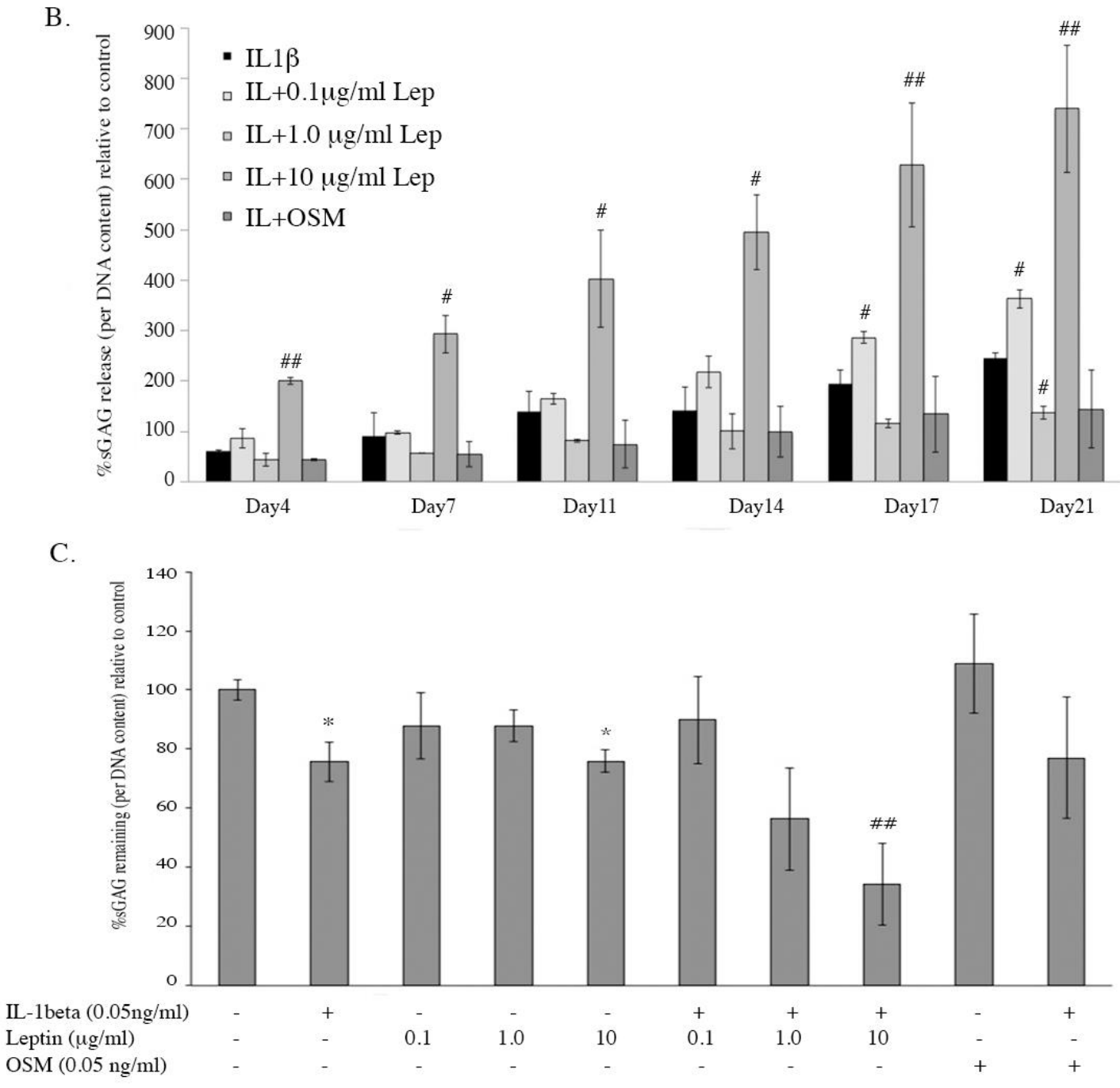

Figure 4. The level of sGAGs released into the cultured media (A and B) and the level of sGAGs remaining in the pellets after being cultured for 21 days $(\mathrm{C})$.

Note: *, \# $P<0.05$ and **, \#\# $P<0.01$ * and \# denote significant differences compared to the control and IL1 $\beta$ treated group, respectively. 


\section{Effect of leptin alone and in combination with IL1 $\beta$ on collagen content}

Another important ECM molecule, collagen, was investigated by measuring the hydroxyproline released into the cultured media and the hydroxyproline remaining in the pellet. IL1 $\beta$ significantly increased hydroxyproline released at almost all periods of treatment (Figure 5A) and decreased hydroxyproline remaining in the pellets at the end of treatment (Figure 5C). All concentrations of leptin were able to increase hydroxyproline released into the media and decrease hydroxyproline remaining in the pellets when compared to the control. Only the combination of IL $1 \beta$ and $10 \mu \mathrm{g} / \mathrm{ml}$ leptin was found to significantly decrease the hydroxyproline remaining when compared to the IL1 $\beta$ treated alone. The collagen remaining in the pellets was also investigated by histological analysis using Masson's trichrome staining, which stained the cell and cytoplasm red and the collagen blue (Figure 3). The intensity of the light blue color indicated the amount of collagen in the ECM of the pellets, which showed results similar to the measurement of hydroxyproline (Figure 5C). The intensity of collagen significantly decreased in IL1 $\beta$, IL1 $\beta+O S M, 10 \mu \mathrm{g} / \mathrm{ml}$ leptin treated conditions and all IL1 $\beta+$ leptin treated conditions when compared to that of the control group. These results suggest that IL1 $\beta$ is able to induce pathological condition by decreasing sGAG and collagen contents in the pellets. Interestingly, leptin, especially at the concentration of 10 $\mu \mathrm{g} / \mathrm{ml}$, showed the same results as IL1 $\beta$. Additionally, leptin was found to have an additive effect in combination with IL $1 \beta$ on the induction of pathological condition. 
A.

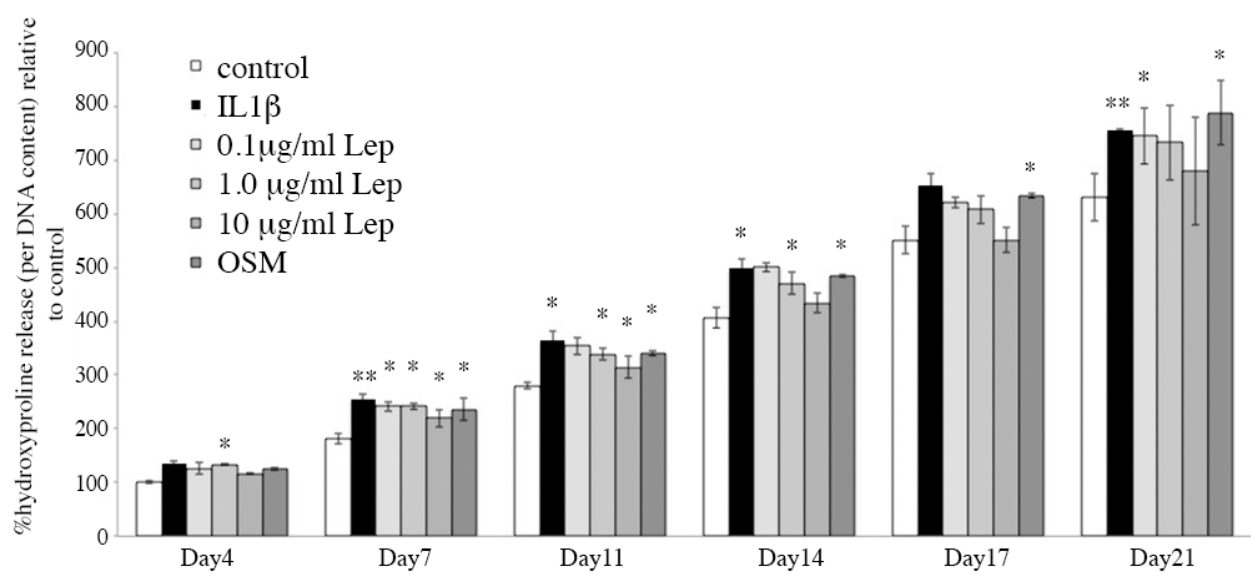

B.

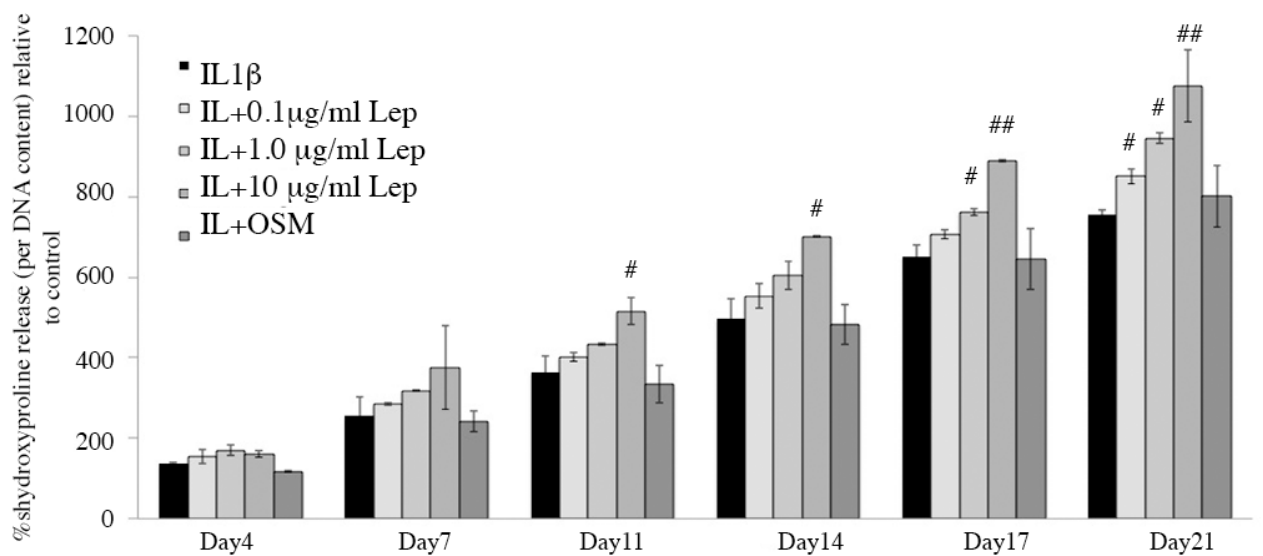

C.

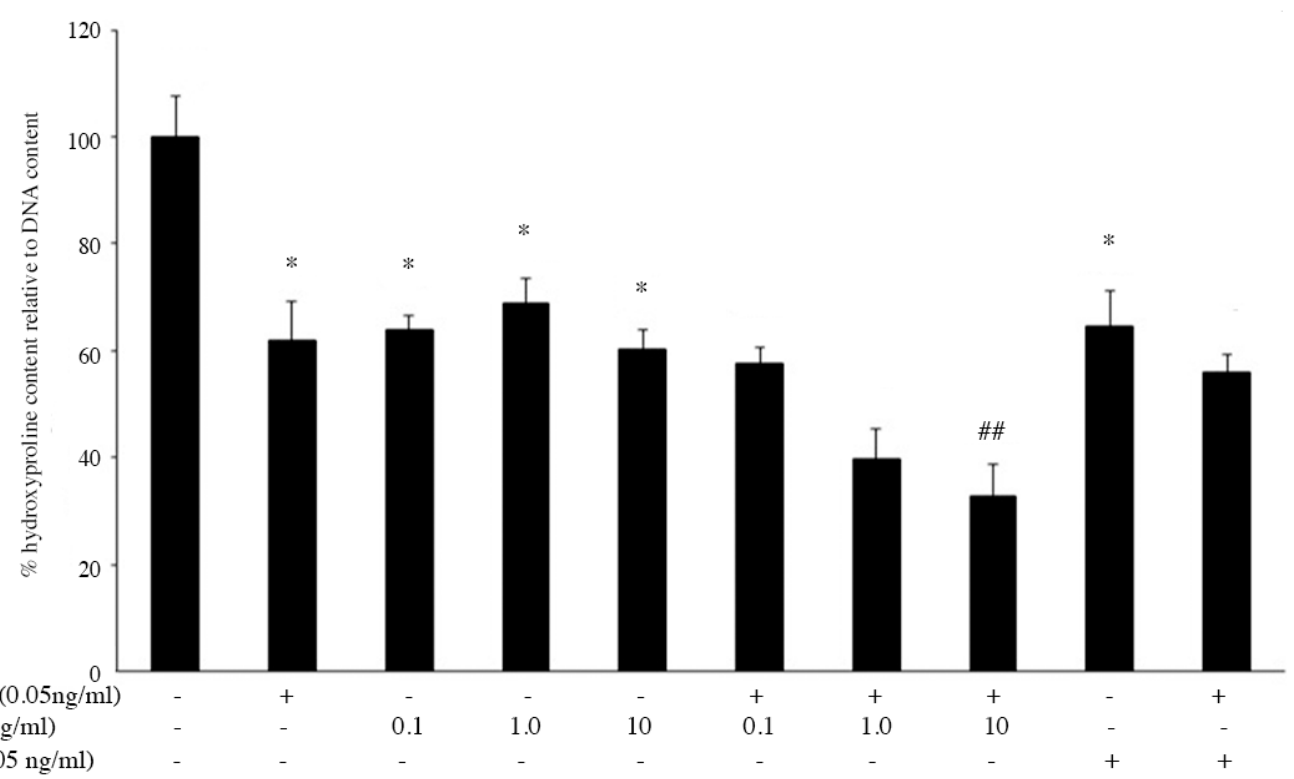

Figure 5. The level of hydroxyproline released into culture media (A and B) and the level of hydroxyproline remaining in the pellets after being cultured for 21 days $(\mathrm{C})$.

Note: *, \# $P<0.05$ and **, \#\# $P<0.01$ * and \# denote significant differences compared to the control and IL1 $\beta$ treated group, respectively. 


\section{Effect of leptin alone and in combination with IL1 $\beta$ on anabolic gene expression}

mRNA expression of the ECM molecules, including ACAN, COL2A1 and COL1A1, examined by real-time RT-PCR can be used to better understand the effect of leptin on ECM molecule production of chondrocytes in the pellet. The results, as displayed in Figure 6, found that IL1 $\beta$ decreased the expression of $A C A N$ and could induce the expression of COL1Al leading to the loss of specific phenotype of the chondrocytes but had no effect on COL2A1 expression. Leptin alone $(1.0$ and $10 \mu \mathrm{g} / \mathrm{ml})$ had the same effect as IL1 $\beta$, with decreased $A C A N$ expression and increased COL1Al expression when compared to the control. Moreover, leptin had an additive effect in combination with IL1 $\beta$ on the reduction of $A C A N$ expression and induction of COL1Al expression. This additive effect of leptin with IL1 $\beta$ was greater than that of OSM with IL1 $\beta$. The data suggests that leptin alone $(1.0$ and $10 \mu \mathrm{g} / \mathrm{ml})$ can reduce GAG production and induce the dedifferentiation of the chondrocytes in the pellets, with effects similar to IL1 $\beta$. Interestingly, leptin also had the capacity to increase the effect of IL1 $\beta$. 
A.

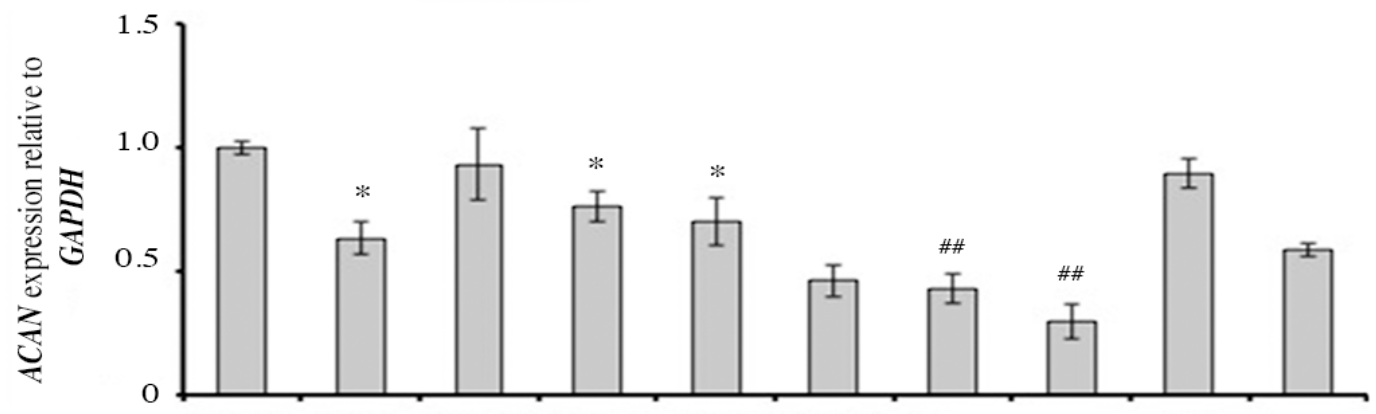

B.

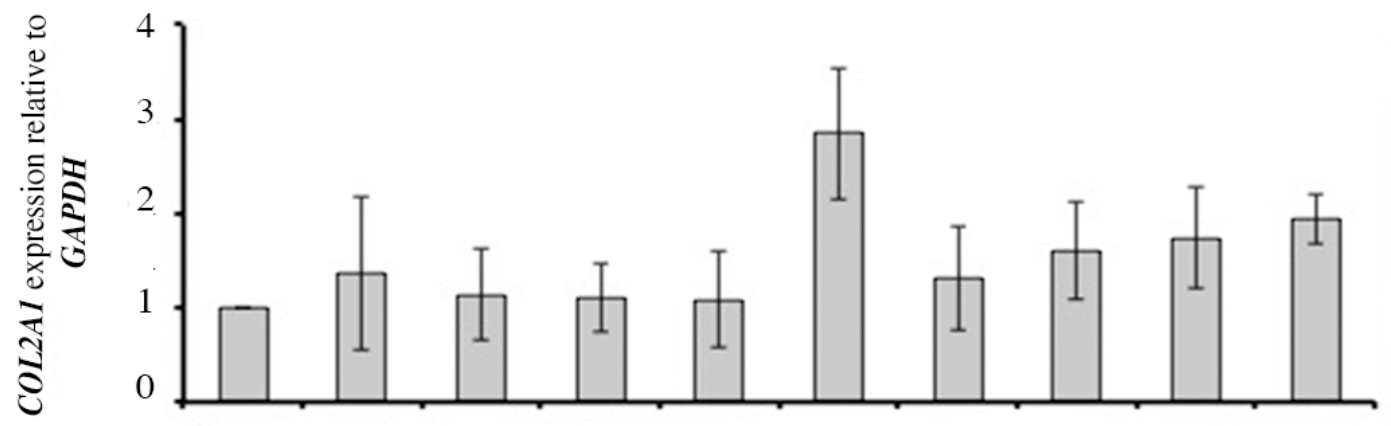

C.

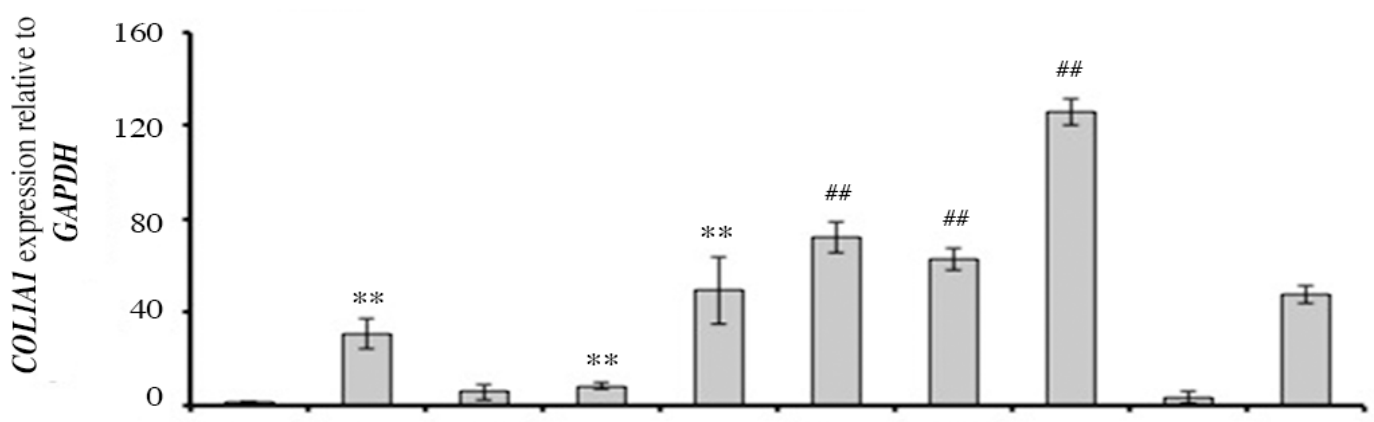

D.

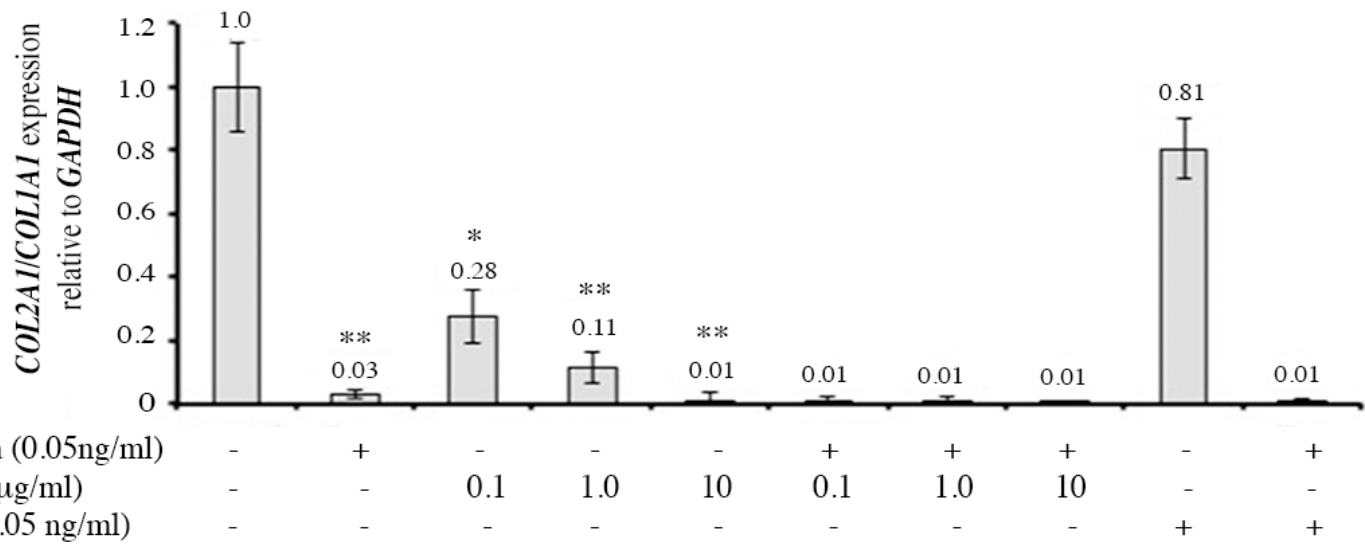

Figure 6. The levels of anabolic gene expression including $A C A N$ (A), COL2A1(B) and COL1A1 (C) and the ratio of COL2A1:COL1A1 (D).

Note: *, \# $P<0.05$ and **, \#\# $P<0.01$ * and \# denote significant differences compared to the control and IL1 $\beta$ treated group, respectively. 


\section{Effect of leptin alone and in combination with IL1 $\beta$ on the expression of catabolic factors}

The effects of leptin alone and leptin combination with IL1 $\beta$ on the expressions of catabolic factors, including MMP3 and MMP13 mRNA and protein expressions, were investigated using real-time RT-PCR and ELISA, respectively. The expressions of the major catabolic factors that degrade ECM molecules of cartilage, $M M P 3$ and $M M P 13$ were found to be increased by IL1 $\beta$, (Figure 7) when compared to the control. Leptin alone $(10 \mu \mathrm{g} / \mathrm{ml})$ increased the expression of MMP3 and MMP13 and had an additive effect with IL1 $\beta$, similar to the effect of OSM. The level of protease enzymes, MMP3 and MMP13, were measured in the conditioned media at Day 11 of the culture. The results found that IL1 $\beta$ significantly increased MMP3 and MMP13 levels in the culture media (Figure 8) and leptin alone also induced both enzyme levels. All leptin concentrations $(0.1,1.0,10 \mu \mathrm{g} / \mathrm{ml})$ had an additive effect with IL1 $\beta$ on the induction of MMP3 level, whereas only the highest concentration $(10 \mu \mathrm{g} / \mathrm{ml})$ had additive effect with IL1 $\beta$ in increasing MMP13 level. The results suggest that, leptin alone especially at $10 \mu \mathrm{g} / \mathrm{ml}$ can induce the expression of protease enzymes, MMP3 and MMP13, at both mRNA and protein levels, and moreover, leptin has additive effects with IL1 $\beta$ on the inductions of those MMP enzymes.

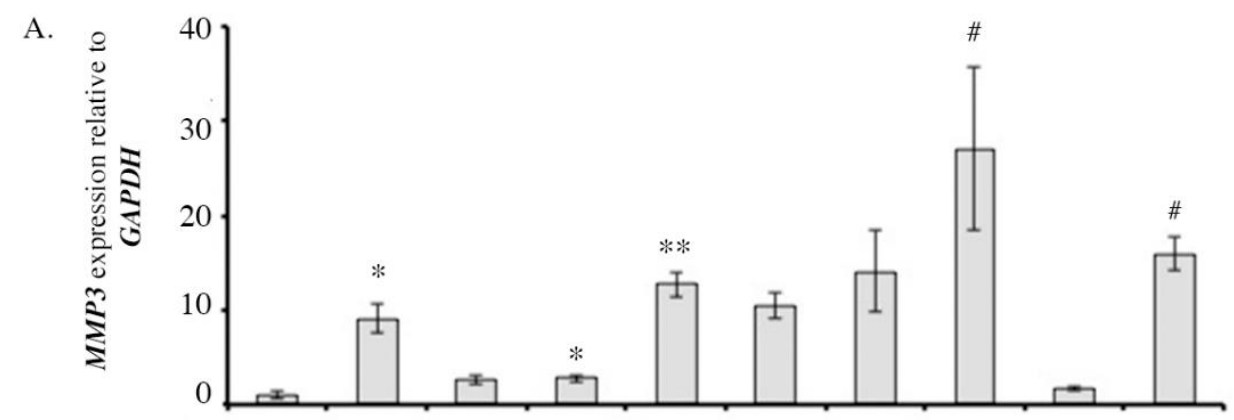

B.

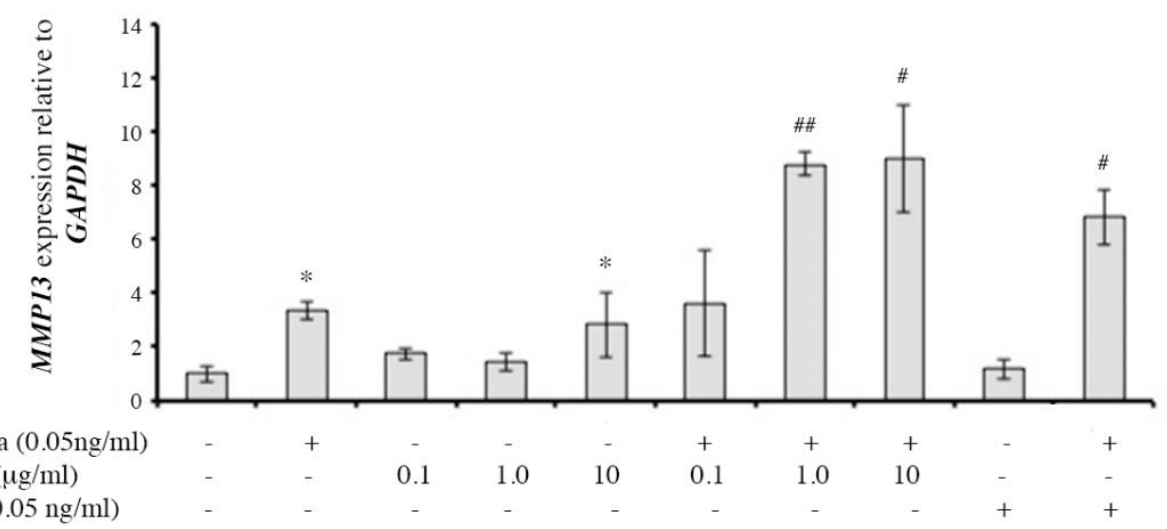

Figure 7. The level of $M M P 3$ and $M M P 13$ gene expressions investigated by realtime PCR.

Note: *, \# $P<0.05$ and **, \#\# $P<0.01$ * and \# denote significant differences compared to the control and IL1 $\beta$ treated group, respectively. 
A.

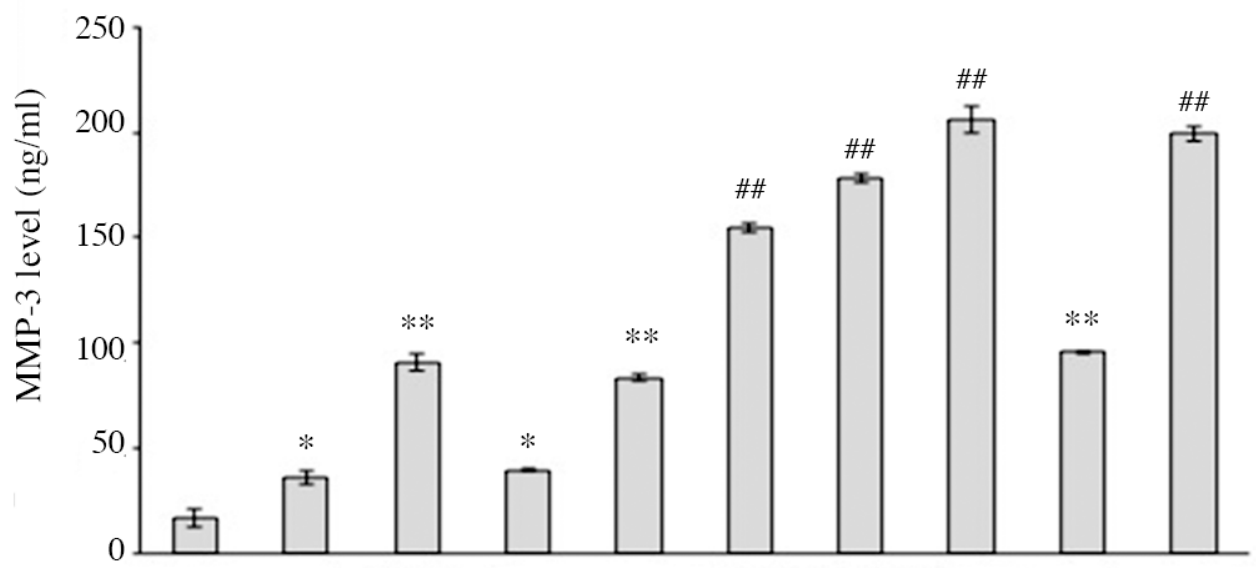

B.

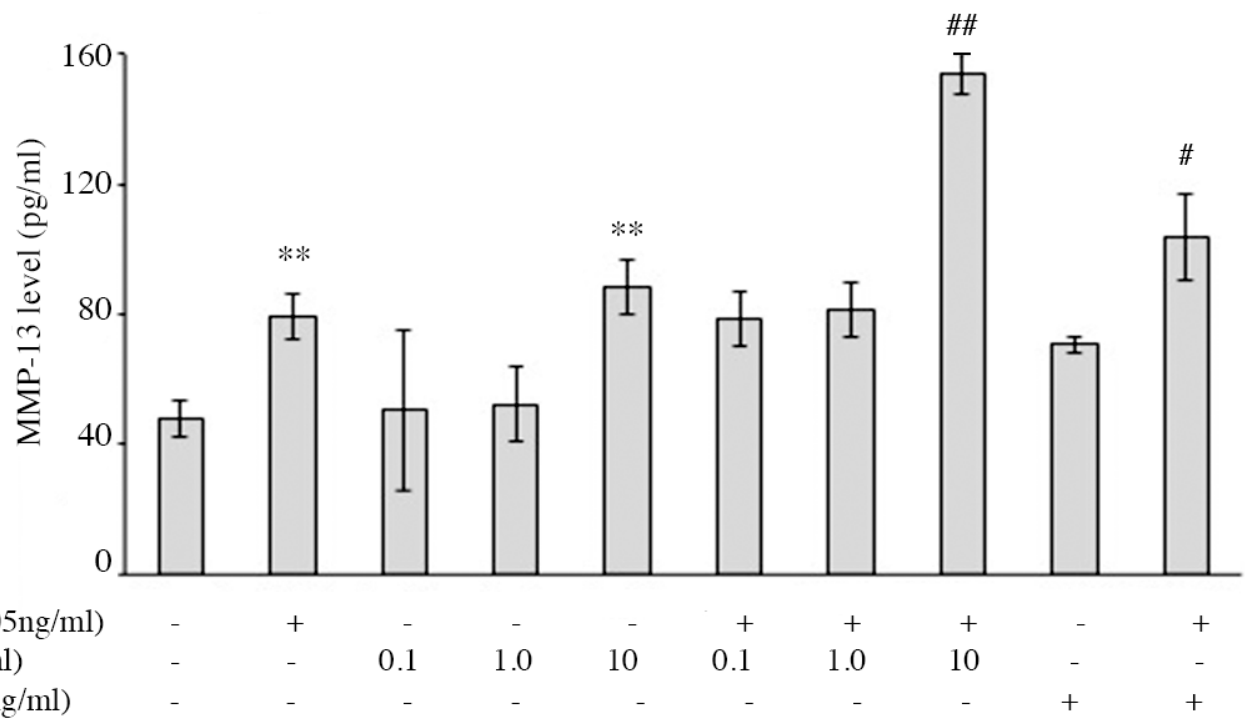

Figure 8. The level of MMP3 and MMP13 enzymes in cultured media measured by ELISA.

Note: *, \# $P<0.05$ and $* *$, \#\# $P<0.01$ * $^{*}$ and \# denote significant differences compared to the control and IL1 $\beta$ treated group, respectively.

\section{DISCUSSION}

Osteoarthritis (OA) is a major cause of disability among the elderly and is also common in obese patients. Obesity is considered an important risk factor for the development and progression of OA in both weight-bearing and low-weightbearing joints. For weight-bearing joints, mechanical force is known to be directly involved in the progression of OA, however, does not explain the development of OA in lower load-bearing joints, such as in the hands and fingers. Systemic cytokines, especially leptin, that systemically increases in obese patients, may be the link between OA in lower load-bearing joints and obesity (Rasheed et al., 2010). There have been many studies that investigated the effect of leptin alone or in combination with other inflammatory cytokines on chondrocyte metabolism, however, results were inconclusive (Figenschau et al., 2001; 
Koskinen et al., 2011; McNulty et al., 2011) Our previous study on the porcine cartilage explant found that only supra-pathological concentration of leptin $(10 \mu \mathrm{g} / \mathrm{ml})$ could induce cartilage degradation, while pathological concentration $(0.1 \mu \mathrm{g} / \mathrm{ml})$ could not. Moreover, this concentration of leptin demonstrated the ability to induce the expression of MMP3 and MMP13 in the monolayer culture of human chondrocytes. Supra-pathological concentration of leptin was found to have synergistic effects with IL- $1 \beta$ on the induction of those protease enzymes, while the pathological concentration used in that study had no effect. (Phitak et al., 2018). Therefore, limitations in the models used in the previous study were considered. Since monolayer culture was used in the previous study, the dedifferentiation stage of chondrocytes in the model may have been involved in the response of leptin. This study examined the effect of pathological $(0.1 \mu \mathrm{g} / \mathrm{ml})$ and supra-pathological (1.0-10 $\mu \mathrm{g} / \mathrm{ml})$ concentrations of leptin in primary human chondrocytes cultured in a pellet model to minimize the problems related to dedifferentiation, in order to more precisely understand the effect of leptin on chondrocytes. Additionally, the synergistic or additive effect of leptin with IL-1 $\beta$ was also investigated.

The supra-pathological concentrations of leptin displayed the capacity to decrease ECM molecules including sGAG and collagen in the pellets, due to its ability to reduce the expression of $A C A N$ gene. For collagen, leptin had no effect on COL2Al expression but was able to induce the dedifferentiation of chondrocyte by up-regulation of COL1A1 expression and reduce the ECM content by induction of MMP3 and MMP13 productions. These results were similar to the investigation in human monolayer culture (Phitak et al., 2018). In the pathological concentration $(100 \mathrm{ng} / \mathrm{ml})$ of leptin, this study found that this concentration could decrease the collagen content in the pellet, which may be a result of its ability to induce MMP3 expression. Interestingly, the pathological concentration had no effect on GAG content, though, the GAG was more easily degraded by protease enzymes compared to the collagen. The results on the induction of dedifferentiation by up-regulation of COL1A1 and on the induction of MMP3 expression showed that supra-pathological concentrations of leptin had an additive effect with IL1 $\beta$, similar to its effect in monolayer culture, and additionally found that the pathological concentration also had an additive effect with IL1 $\beta$ in this model.

In the pellet culture model, the effect of pathological concentrations of leptin and its additive effect with IL1 $\beta$ was better observed. However, the results found that the effect of leptin alone was much less than the effect of IL1 $\beta$, and the additive effect in combination with IL1 $\beta$ was also less than the additive effect of IL1 $\beta$ in combination with OSM; a well-known cytokine that has capacity to synergize IL1 $\beta$ effect. While the supra-pathological concentrations of leptin had almost the same effect as IL1 $\beta$ and had a higher additive effect with IL1 $\beta$ in comparison to the additive effect with OSM. 
The results suggest that leptin may be a linker cytokine that can induce OA initiation and progression in obese patients. However, there are potential confounding factors and limitations to this study. Normal leptin levels in human peripheral blood has been found to be related to gender and age, where leptin levels in females were higher than in males, especially after 12 years of age (Carraro and Ruiz-Torres, 2006; Witonski et al., 2010). Therefore, it may be important to consider age and gender specific data to clarify the effect of leptin, which had not been accounted for in this study. Additionally, in this study, normal intact cartilages were collected from lower limbs of osteosarcoma patients that had previously undergone neoadjuvant chemotherapy for a period of 3 months, and it is possible that the isolated chondrocytes may have been affected by the chemotherapy. Another limitation is that the peripheral leptin level of each donor was not measured, which could have been used to explain the different responses to leptin among the donors. Furthermore, as only small amounts of intact cartilage were able to be collected from each donor, the expansion of primary cells by monolayer culture was necessary to obtain enough cells for the pellet culture. Lower passage of used cells may have provided more precise results, especially for the dedifferentiation. Finally, the cartilage samples collected from the joints of the lower limbs were primarily of load-bearing joints, where the mechanical force could have affected the response of isolated chondrocytes to leptin.

\section{ACKNOWLEDGEMENTS}

This study was financial supported by Faculty of Medicine Research Fund, Chiang Mai University, Thailand (to Thanyaluck Phitak, grant number: 0282561). The authors would like to thank the Thailand Excellence Center for Tissue Engineering and Stem Cells, Faculty of Medicine, Chiang Mai University, Thailand for providing the instruments used in this study.

\section{REFERENCES}

Ahima, R.S., Prabakaran, D., Mantzoros, C., Qu, D., Lowell, B., Maratos-Flier, E., and Flier, J.S. 1996. Role of leptin in the neuroendocrine response to fasting. Nature. 382(6588): 250-252. https://doi.org/10.1038/ 382250a0

Carraro, R., and Ruiz-Torres, A. 2006. Relationship of serum leptin concentration with age, gender, and biomedical parameters in healthy, non-obese subjects. Arch Gerontol Geriatr. 43(3): 301-312. https://doi.org/ 10.1016/j.archger.2005.11.004 
Considine, R.V., Sinha, M.K., Heiman, M.L., Kriauciunas, A., Stephens, T.W., Nyce, M.R., Ohannesian, J.P., Marco, C.C., McKee, L.J., Bauer, T.L. et al. 1996. Serum immunoreactive-leptin concentrations in normal-weight and obese humans. The New England Journal of Medicine. 334(5): 292-295. https://doi.org/ 10.1056/NEJM199602013340503

de Boer, T.N., van Spil, W.E., Huisman, A.M., Polak, A.A., Bijlsma, J.W., Lafeber, F.P., and Mastbergen, S.C. 2012. Serum adipokines in osteoarthritis; comparison with controls and relationship with local parameters of synovial inflammation and cartilage damage. Osteoarthritis Cartilage. 20(8): 846-853. https://doi.org/10.1016/j.joca.2012.05.002.

Farndale, R.W., Buttle, D.J., and Barrett, A.J. 1986. Improved quantitation and discrimination of sulphated glycosaminoglycans by use of dimethylmethylene blue. Biochimica et Biophysica Acta. 883(2): 173177.https://doi.org/10.1016/0304-4165(86)90306-5

Figenschau, Y., Knutsen, G., Shahazeydi, S., Johansen, O., and Sveinbjornsson, B. 2001. Human articular chondrocytes express functional leptin receptors. Biochemical and Biophysical Research Communications. 287(1): 190-197. https://doi.org/10.1006/bbrc.2001.5543

Goldner, J. 1938. A modification of the masson trichrome technique for routine laboratory purposes. The American Journal of Pathology. 14(2): 237-243.

Ito, A., Aoyama, T., Iijima, H., Nishitani, K., Tajino, J., and Kuroki, H. 2019. Periodic mild heat stimuli diminish extracellular matrix synthesis in pellet cultured human chondrocytes. BMC Research Notes. 12(1): 16.

Kolar, K. 1990. Colorimetric determination of hydroxyproline as measure of collagen content in meat and meat products: Nmkl collaborative study. Journal-Association of Official Analytical Chemists. 73(1): 54-57.

Koshy, P.J., Lundy, C.J., Rowan, A.D., Porter, S., Edwards, D.R., Hogan, A., Clark, I.M., and Cawston, T.E. 2002. The modulation of matrix metalloproteinase and adam gene expression in human chondrocytes by interleukin-1 and oncostatin m: A time-course study using real-time quantitative reverse transcription-polymerase chain reaction. Arthritis \& Rheumatoly. 46(4): 961-967. https://doi.org/10.1002/art.10212

Koskinen, A., Vuolteenaho, K., Nieminen, R., Moilanen, and T., Moilanen, E. 2011. Leptin enhances mmp-1, mmp-3 and mmp-13 production in human osteoarthritic cartilage and correlates with mmp- 1 and mmp-3 in synovial fluid from oa patients. Clinical and Experimental Rheumatology. 29(1): 57-64.

Ku, J.H., Lee, C.K., Joo, B.S., An, B.M., Choi, S.H., Wang, T.H., and Cho, H.L. 2009. Correlation of synovial fluid leptin concentrations with the severity of osteoarthritis. Clinical Rheumatology. 28(12): 1431-1435. https:// doi.org/ 10.1007/s10067-009-1242-8 
Lin, Z., Fitzgerald, J.B., Xu, J., Willers, C., Wood, D., Grodzinsky, A.J., and Zheng, M.H. 2008. Gene expression profiles of human chondrocytes during passaged monolayer cultivation. Journal of Orthopaedic Research. 26(9): 1230-1237. https://doi.org/10.1002/jor.20523

Livak, K.J., and Schmittgen, T.D. 2001. Analysis of relative gene expression data using real-time quantitative pcr and the 2(-delta delta $\mathrm{c}(\mathrm{t}))$ method. Methods. 25(4): 402-408. https://doi.org/10.1006/meth.2001.1262

McNulty, A.L., Miller, M.R., O'Connor, S.K., and Guilak, F. 2011. The effects of adipokines on cartilage and meniscus catabolism. Connective Tissue Research. 52(6): 523-533.https://doi.org/10.3109/03008207.2011.597902

Musumeci, G., Castrogiovanni, P., Trovato, F.M., Imbesi, R., Giunta, S., Szychlinska, M.A., Loreto, C., Castorina, S., and Mobasheri, A. 2015. Physical activity ameliorates cartilage degeneration in a rat model of aging: A study on lubricin expression. Scandinavian Journal of Medicine \& Science in Sports. 25(2): 222-230. https://doi.org/10.1111/sms.12290

Otero, M., Lago, R., Gomez, R., Lago, F., Dieguez, C., Gomez-Reino, J.J., and Gualillo, O. 2006. Changes in plasma levels of fat-derived hormones adiponectin, leptin, resistin and visfatin in patients with rheumatoid arthritis. Annals of the Rheumatic Diseases. 65(9): 1198-1201. https:// doi.org/10.1136/ard.2005.046540

Phitak, T., Boonmaleerat, K., Pothacharoen, P., Pruksakorn, D., and Kongtawelert, P. 2018. Leptin alone and in combination with interleukin1-beta induced cartilage degradation potentially inhibited by epa and dha. Connective Tissue Research. 59(4): 316-331. https://doi.org/10.1080/ 03008207.2017.1385605

Phitak, T., Pothacharoen, P., Settakorn, J., Poompimol, W., Caterson, B., and Kongtawelert, P. 2012. Chondroprotective and anti-inflammatory effects of sesamin. Phytochemistry. 80: 77-88. https://doi.org/10.1016/j.phyto chem.2012.05.016

Rasheed, Z., Akhtar, N., and Haqqi, T.M. 2010. Advanced glycation end products induce the expression of interleukin- 6 and interleukin- 8 by receptor for advanced glycation end product-mediated activation of mitogen-activated protein kinases and nuclear factor-kappab in human osteoarthritis chondrocytes. Rheumatology (Oxford). 50(5): 838-851. https://doi.org/ 10.1093/rheumatology/keq380

Roussel, J.D., and Stallcup, O.T. 1965. Activity of lactic dehydrogenase and its isozymes in bovine semen. Journal of Dairy Science. 48(11): 1506-1510. https://doi.org/ 10.3168/jds.S0022-0302(65)88507-1

Ruggiero, F., Petit, B., Ronziere, M.C., Farjanel, J., Hartmann, D.J., and Herbage, D. 1993. Composition and organization of the collagen network produced by fetal bovine chondrocytes cultured at high density. Journal of Histochemistry and Cytochemistry. 41(6): 867-875. https://doi.org/ 10.1177/41.6.8315278 
Schulze-Tanzil, G., de Souza, P., Villegas Castrejon, H., John, T., Merker, H.J., Scheid, A., and Shakibaei, M. 2002. Redifferentiation of dedifferentiated human chondrocytes in high-density cultures. Cell and Tissue Research. 308(3): 371-379. https://doi.org/10.1007/s00441-002-0562-7

Srisuthtayanont, W., Pruksakorn, D., Kongtawelert, P., and Pothacharoen, P. 2017. Effects of sesamin on chondroitin sulfate proteoglycan synthesis induced by interleukin-1beta in human chondrocytes. BMC Complementary Medicine and Molecular Medicine. 17(1): 286. https://doi. org/10.1186/s12906-017-1805-1

Trayhurn, P. 2005. The biology of obesity. Proceedings of the Nutrition Society. 64(1): 31-38. https://doi.org/10.1079/pns2004406

Witonski, D., Wagrowska-Danilewicz, M., Keska, R., Raczynska-Witonska, G., and Stasikowska-Kanicka, O. 2010. Increased interleukin 6 and tumour necrosis factor alpha expression in the infrapatellar fat pad of the knee joint with the anterior knee pain syndrome: A preliminary report. Polish Journal of Pathology. 61(4): 213-218.

Witt, A., Salamon, A., Boy, D., Hansmann, D., Buttner, A., Wree, A., Bader, R., and Jonitz-Heincke, A. 2017. Gene expression analysis of growth factor receptors in human chondrocytes in monolayer and $3 \mathrm{~d}$ pellet cultures. International Journal of Molecular Medicine. 40(1): 10-20. https://doi.org/ 10.3892/ijmm.2017.2994

Yusuf, E., Nelissen, R.G., Ioan-Facsinay, A., Stojanovic-Susulic, V., DeGroot, J., van Osch, G., Middeldorp, S., Huizinga, T.W.J., and Kloppenburg, M. 2010. Association between weight or body mass index and hand osteoarthritis: A systematic review. Annals of the Rheumatic Diseases. 69(4):761-765. https://doi.org/10.1136/ard.2008.106930 